\title{
Knowledgeable Artefacts: The role of performance documentation in PaR
}

\author{
DANI ABULHAWA, Plymouth University/Sheffield Hallam University
}

\begin{abstract}
The documentation of research practice is a central concern for practice-based researchers, whose projects involve a consideration of multiple sites in which knowledge is produced and experienced.
\end{abstract}

My own practice as research $\mathrm{PhD}$ involved a series of performative explorations of gendered play in the built environment. The documentation I produced was in the form of artists' pages (inspired by the regular feature in performance research), containing diary entries and responses overheard from members of the public, as well as comments about my engagement with each examiner. Whilst writing up my research, I found it necessary to consider the knowledge I had gained through the process of documenting and from an engagement with the documentation itself.

My article explores the role of documentation as another site of knowledge production and performance within the thesis.

\section{KEYWORDS}

Performance, documentation, practice-as-research

Over the past two decades, practice as research has become increasingly important within the academic disciplines of the performing arts, as artists have explored the knowledge(s) contained within and understood through their various different forms of practice. This development has raised questions about the institutional validation of practical forms of research (Piccini 2002, n.p.), critical frameworks and methodologies, and the process of examination of practice as research within the academy.

The PARIP project, which ran between 2001 and 2006 - directed by Professor Baz Kershaw and the Department of Drama: Theatre, Film, Television at Bristol University - sought to address some of these issues through aims that included understanding the range of practice as research being undertaken within the UK, exploring key issues, and consulting on a range of projects (PARIP nd, online). The PARIP project incorporated three general conferences (the final one of an international scope), as well as several local seminars across the four years, which involved a broad range of academics, highlighting how significant the project was to performance-oriented research communities.

The recently established Performance Philosophy network and journal (launched April 2015), dedicated to exploring the relationship between philosophy and 
performance, indicates the extent to which PARIP and the wealth of scholarly attention paid to practice as research in the following years (Nelson 2006, Freeman 2010, Kershaw and Nicholson 2011, Nelson 2013, amongst others), has helped to establish a firm foundation for performance practices as sites for knowledge production and philosophical enquiry within the academy.

Robin Nelson has defined a 'triangular model' for understanding the multi-mode epistemology of practice as research (2013, 37; Nelson 2006), which incorporates 'know how' - tacit and embodied forms of knowledge, ' know-what' - the tacit made explicit through critical reflection, and 'know-that' - conceptual frameworks and 'outsider' knowledge. The arts 'praxis' (theory imbricated with practice) sits at the centre of this model, fed by these multiple epistemological methods, which in turn feed each other in a fluid dialogue.

Relatedly, Baz Kershaw articulates this multi-mode epistemology as the practice as research bandwidth. He states,

'[a]s PaR is pursued through time-space events its transmission - the means by which any knowledge/understanding/insight it produces are communicated is always multi-modal... this diversity of dissemination reflects the hybridity of its specific methods of enquiry, as it involves unique 'messages' that constitute a singular chorus, the PaR bandwidth.

$(2011,66)$

Practice as researchers seek not only to uncover knowledge through different types of practice (performance, dance, the production of objects, as well as writing and reading), they seek to disseminate their findings through the most effective and appropriate means.

This concern over effective and appropriate means of presentation is not merely a concern for artistic integrity or rigour. The $\mathrm{PaR}$ bandwidth can also be understood as a response to what Tom Holert discusses as the hegemonic knowledge economy of the academy (2009, n.p.). By presenting artistic research in alternative formats to the traditional written thesis, perhaps through performance, artwork, or installation, etc. the dissemination of research has a reception outside of the university - in a very different form and 'language' to the traditional written thesis - and to a wider, general public.

In respect of the fact that knowledge is understood as contained within practical elements, as much as the written thesis, the award of a practice as research $\mathrm{PhD}$ in $\mathrm{UK}$ HEIs typically requires an examination of practice, alongside the submission of a written thesis, as well as documentation of the practice seen by examiners. Issues around the role different elements of the thesis play within the research are a key concern for practice as researchers.

My own practice as research $\mathrm{PhD}$ began as an enquiry around play in the public built environment, following my history of involvement in skateboarding. Recognising my status as 'female' skateboarder, and noticing similarities between the urban practices of skateboarding, parkour and rollerblading in their attraction to boys and men, I questioned why girls and women were not equally interested in these forms of play. I 
wondered what the nature of this connection was between urban play and gender, and I questioned how the public built environment might be understood as a gendered space.

Sources such as Doreen Massey's Space, Place and Gender (1994), Rosa Ainsley's edited volume, New Frontiers of Space, Bodies and Gender (1998) and Jane Rendell, Barbara Penner and Iain Borden's edited volume, Gender, Space, Architecture: An Interdisciplinary Introduction (2000), provided an excellent foundation for the consideration of how space is produced through, and how places are defined by, practices that do not treat people as equal and active subjects. Borden's Skateboarding, Space and the City: Architecture and the Body (2001) offers an excellent theorising of skateboarding in relation to architectural theory and spatial production. He includes a chapter on skateboarding, as 'subculture', where he makes reference to female involvement and representations of women in skateboarding graphics, which highlights some of the inherent sexism within skateboarding.

Offering a clear reasoning for why women and girls have less of an involvement in play more broadly, several sources spanning at least the past 35 years, explore women's involvement in sport, and argue, in a range of nuanced ways, that sports, games and organised forms of play typically preserve forms of patriarchal control and gender stereotypes (Bennett 1987, Birrell and Richter 1987, Bryson 1987, Vaughter 1994, Richman and Shaffer 2000, Strandbu and Hegna 2006, Knijnik 2012). Several of these sources cite restrictions that have historically been placed on women in their attempts to participate and compete in sporting activities (Knijnik 2012, Richman and Shaffer 2000). The literature suggests that sports (and the wider field of playful activity enjoyed by adults) do not always support women's participation in various ways, alongside narrow definitions of femininity that discourage female involvement.

My research methods included examining the work of, particularly, female artists making performance (itself a type of play) in the public built environment, as well as examining relevant literature around the subject, but it became necessary for me to develop a practice of playing as research method. This was particularly important because it was through the experiences of my body - as skateboarder, as girl, as woman - that this enquiry had come to light, and so it seemed highly relevant that my practice would be an appropriate place for the research to be located and that my bodily experience in space would be an ideal site for the knowledge to be understood.

My practice developed from a historical and contemporary understanding of skateboarding and in particular its association with masculinity. Sources like Dogtown and Z-Boys (2001), a film documenting the development of modern skateboarding through the practice of a group of Californian surfers known as the Zephyr team, highlights how a conception of gender in skateboarding is not inherent to a person, a practice or an object, but is inscribed through a culturally defined association of gender with certain objects and the reinforcing of gendered tropes by practitioners; their style of approach, attitude and physical appearance.

In the Dogtown and Z-Boys narrative, the surf-inspired, flowing, non-formalised practice and water-based imagery of the Zephyr team, which might under another set of circumstances be articulated as quite a feminine approach to movement, is presented through a clearly masculine frame, which is identified primarily by the 
attitude of the skaters (Dogtown and Z-Boys 2001). In terms of current skateboarding practice, which has shifted towards the presentation of formalised tricks, incorporating the adoption of a portfolio approach and repetitions of tricks on obstacles to perfect them, there is a stark contrast to that of the earlier Zephyr team, which serves to draw an interesting distinction between these two very different movement forms and the presentations of masculinity they represent.

The notion of a gendered practice is also not simply a reflection of the apparent biological sex of the participant. Protestations made by female skateboarders at the 1975 Del Mar national skateboarding contest, towards Zephyr team rider, Peggy Oke, which is documented in the film Dogtown and Z-Boys (2001), shows how Oke's female peers perceived her as occupying a masculine performance trope. Their complaints to judges that Oke skated 'like a guy' demonstrates how gender is commonly understood as something more constructed and complex than it is fixed, clear and certain.

Taking a cue from the shifting presentations of gender in skateboarding and everyday life, I sought to develop a practice in which I would present a version of femininity, and occupy the city as a playing woman. Presentations of gender are understood as being made in dialogue with a multitude of existing cultural or collective representations as well as personal and embodied conceptions of gender identity. Gender is understood as a presentation of identity that comments upon (perhaps reinforces or perhaps subverts) dominant and essentialist understandings of the relationship between biological sex and behaviour.

I adopted signifiers of femininity, particularly the wearing of a dress. The movement I performed was improvised and vernacular (apparently unskilled) play on street objects, much like the kind of simple playing typically performed by children in public places, like jumping over paving cracks, using straight lines as an imaginary tight-rope, climbing under and over things, and jumping down steps, etc. I avoided standing on benches or anything else used for seating and was considerate of people around me, allowing space for them to move in their own ways, but also making room for myself within specific locations in whatever way I could. In practice, these moments of negotiation reveal much about perceived social status and how people choose to exert this status and control public space.

Another way in which my practice differed was through the lack of skateboard. This decision was made because, as an object skateboards are deeply entrenched in skateboarding culture and an association with masculinity. The use of an object to play with creates mediation between the body and site and serves to legitimise the act of playing through an engagement with a commercial product designed for a specific purpose. It was important to me that my own act of playing allowed me a direct connection to the site, and was understood as a moment of unproductive, autotelic play. Autotelic' play describes that which is an end in itself - it is not undertaken for any other purpose than the experience of the activity in itself.

\section{Performance Documentation}

The documentation I created from the practice seen by my examiners was presented in the form of 'artists' pages', which was inspired by a regular feature in Performance 
Research journal. In this feature a series of pages are set aside for artists to document a piece of performance work that relates to the themes of the issue. The documentation produced for artists' pages take different forms, challenging the possibility of faithfulness in representing the live event. This critical position is in keeping with practice and debate within the field that the documentation of performance primarily functions as generative - developing a range of interpretations and types of response - rather than illustrative, and that the notion of an accurate or objective version of the live event is both unnecessary and impossible to achieve (see De Marinis 1985, Phelan 1993, Auslander 1999, Etchells 1999, Kaye 2000 amongst others).

In his discussion on the performativity of performance documentation, Philip Auslander discusses two ideological approaches to documentation: the documentary and the theatrical. The documentary category sees performance documentation as both evidence of the existence of a performance and a record of the performance event that, traditionally, might enable a reconstruction of that performance. In this category, the documentation is ancillary to the ephemeral performance work. On the other hand, the theatrical category relates to documentation that takes the place of the typical live audience perspective, functioning as the sole means by which the performance work is conveyed to an audience (Auslander 2006) and ultimately being another space in which performance happens.

Auslander's discussion of these two categories in relation to analysis of several performance pieces highlights how much the theatrical and the documentary intertwine with each other, such that documentation of performance is doing all of these things; being a record, providing evidence, and functioning as another site of performance. He writes,

[i]t may well be that our sense of the presence, power, and authenticity of [the performance pieces discussed] derives not from treating the document as an indexical access point to a past event but from perceiving the document itself as a performance that directly reflects an artist's aesthetic project or sensibility and for which we are the present audience.

(Auslander 2006, 9; original emphasis)

Auslander's article is mainly referring to forms of documentation produced on video camera, but the sentiment of his argument can still be applied to other forms of documentation, using still photography, the written word, sketches and animation, and so on. The connection with an originary performance event is central to the argument, but the nature of that connection or relationship is not faithful and accurate, but rather fragmented and partial, and the documentation becomes another performance experience.

In his book on the working processes of internationally renowned performance group, Forced Entertainment, which includes several pieces of documentation from their performance events, artistic director Tim Etchells discusses these documents as 'ghost texts'. He writes, 
[t]he words on the page don't try too hard to evoke the past of performance time; no complex stage directions, or long pedantic notes. Instead I've tried to leave the texts alone as the ghosts they are [...] the ghost text is a clue.

(Etchells 1999, 133)

The notion of a performance document as a ghost coheres with Auslander's position and the blurred theatrical/documentary function of performance documentation. In this way the performance document becomes an afterlife (or series of afterlives) for a performance, and a performance/not-performance that echoes back to a former 'live'.

The documentation produced by an artist is part of a constellation of afterlives that include memories of the work and other forms of evidence, record and detritus that result from the ephemeral performance event. The following four pages contain the documentation for my two PhD performances presented to my examiners. For my $\mathrm{PhD}$ submission these four pages were bound into my thesis before my concluding chapter. The remainder of this article discusses the central elements of this documentation, and its importance as part of the thesis.

\section{Haunts \#1 and \#2}

Throughout my research, I moved away from capturing the performance in mediated form, avoiding anything that might create a frame for the performance - the still camera, the video camera and the invited audience. The presence of a camera, and a camera operator - which incorporates another person involved in the activity, and a potential audience implicit in the recording of this material - creates a frame for the practice that articulates it as an artistic project or for a marketing shot, and this authorises and legitimises the practice as purposeful, profitable and sanctioned. When it came to showing my research to my examiners, and documenting it for my thesis, I had to consider a way to maintain an integrity connected to my research imperatives, whilst also satisfying the academic requirement for a record of the ephemeral aspects of my research enquiry.

The format I adopted for these showings ensured my examiners could witness the practice 'accidentally' in the public built environment, rather than to turn up at a specified time for a conventional show. I negotiated with my examiners to have details of their schedules for a specified period, and found out key information about places they would be visiting and passing through. In turn I visited my examiners hometowns and workplaces, locating myself and performing my practice in sites where I knew they would be passing or dwelling and where they would encounter me. In practice it functioned rather like stalking, but my examiners had given permission for me to follow them on specified days, and they knew that I would be presenting the practical element of my thesis during these times. 


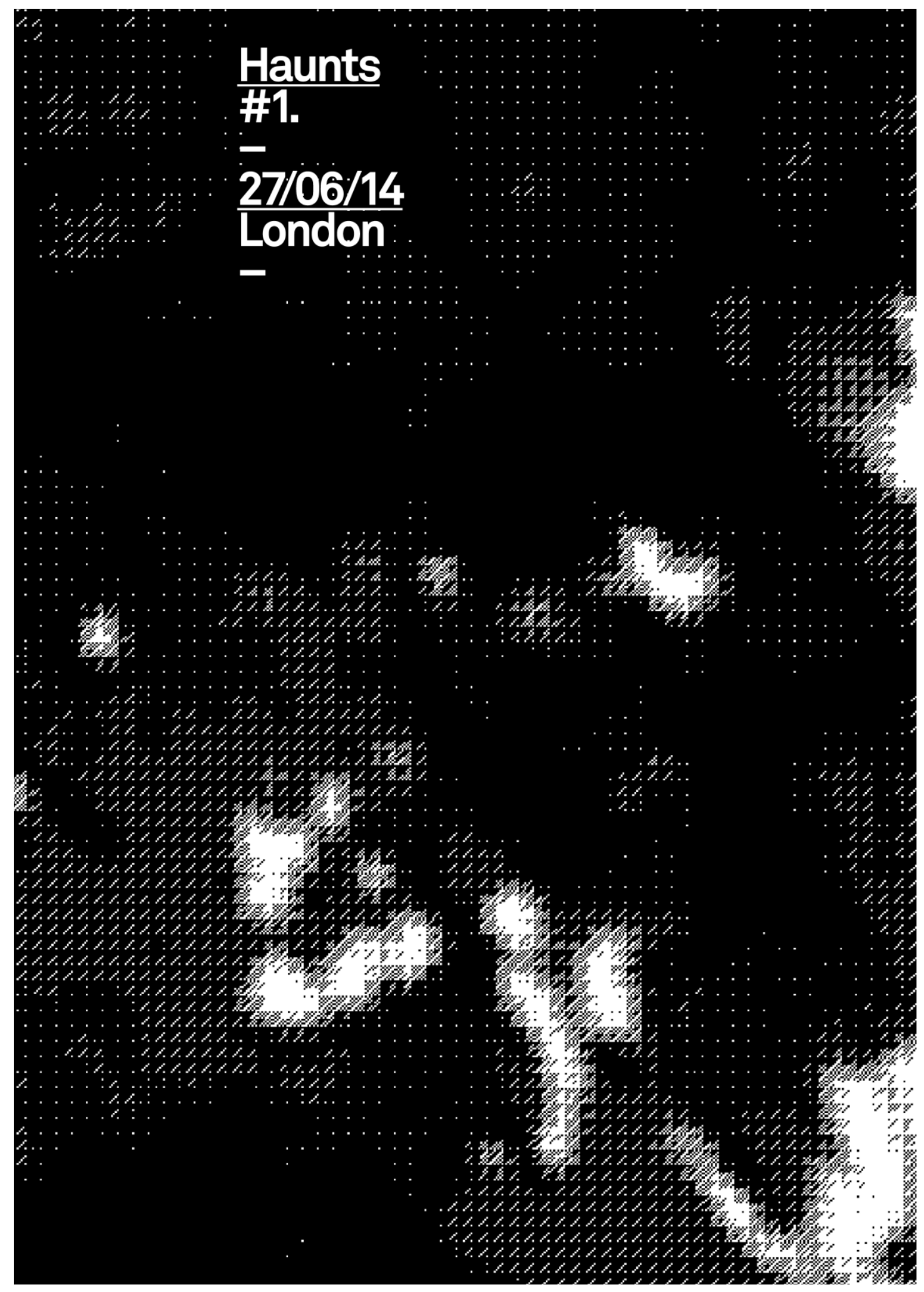




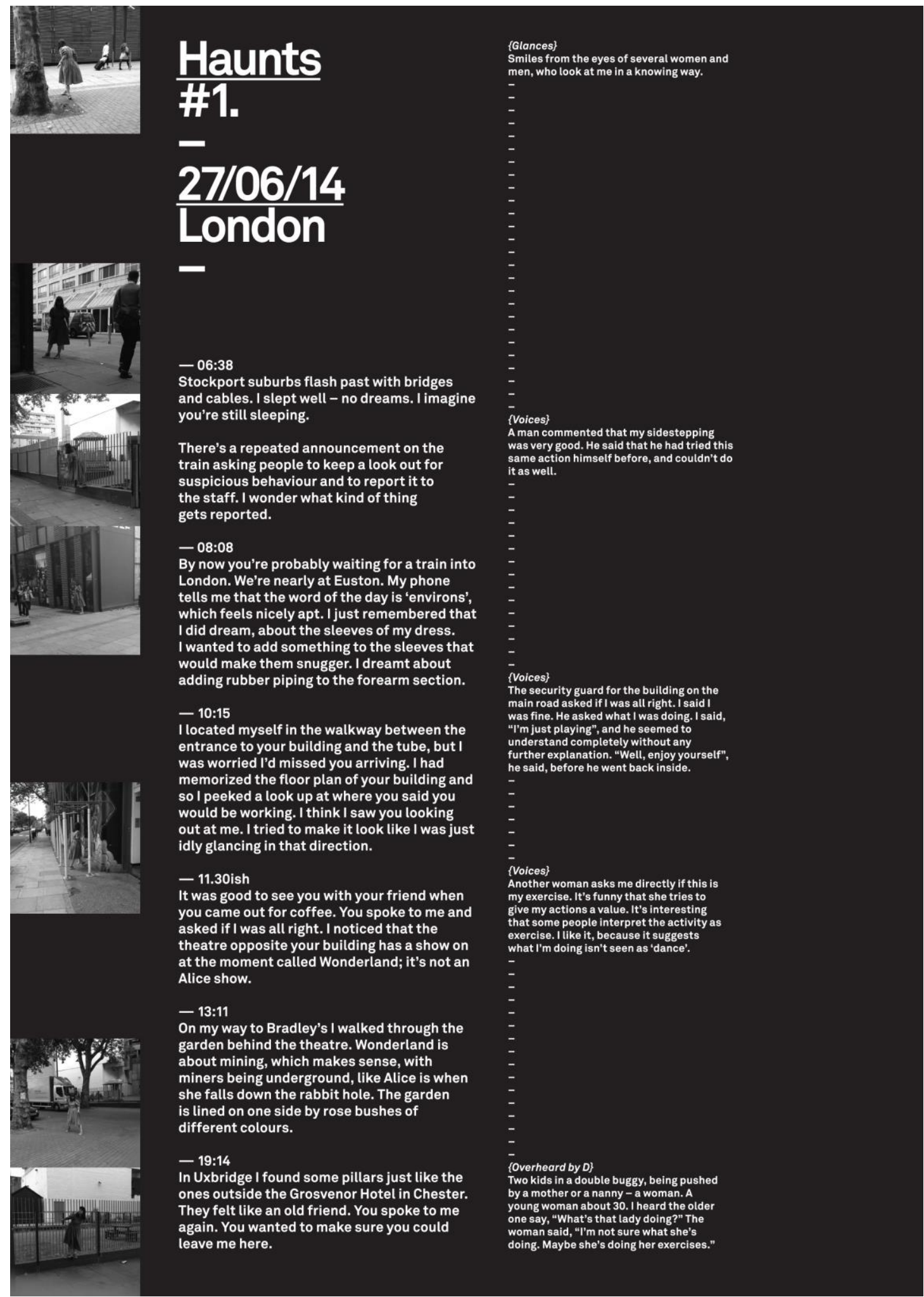




\section{Haunts} \#2.

$12 / 08 / 14+$ $13 / 08 / 14$ Totnes + Plymouth

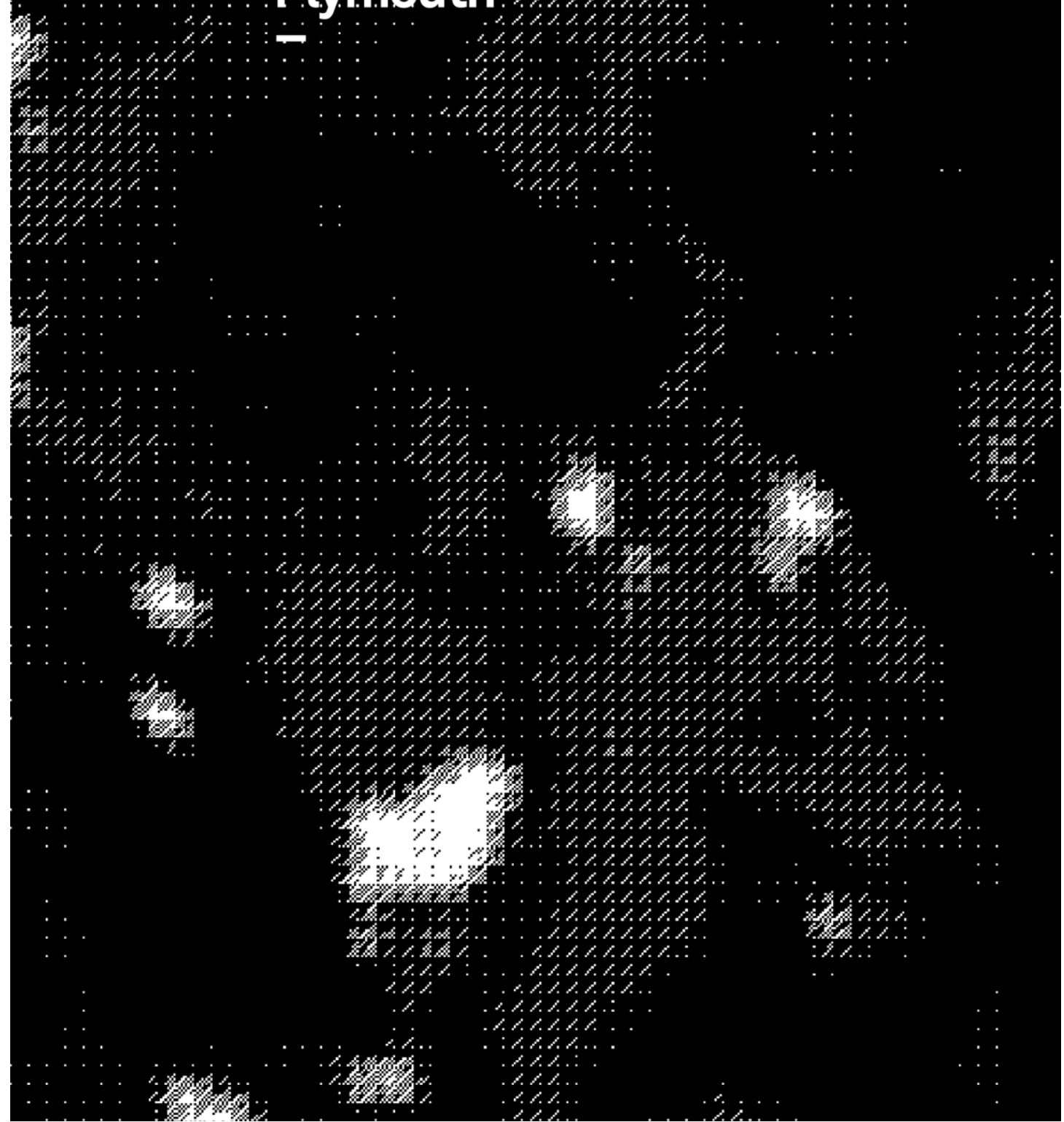




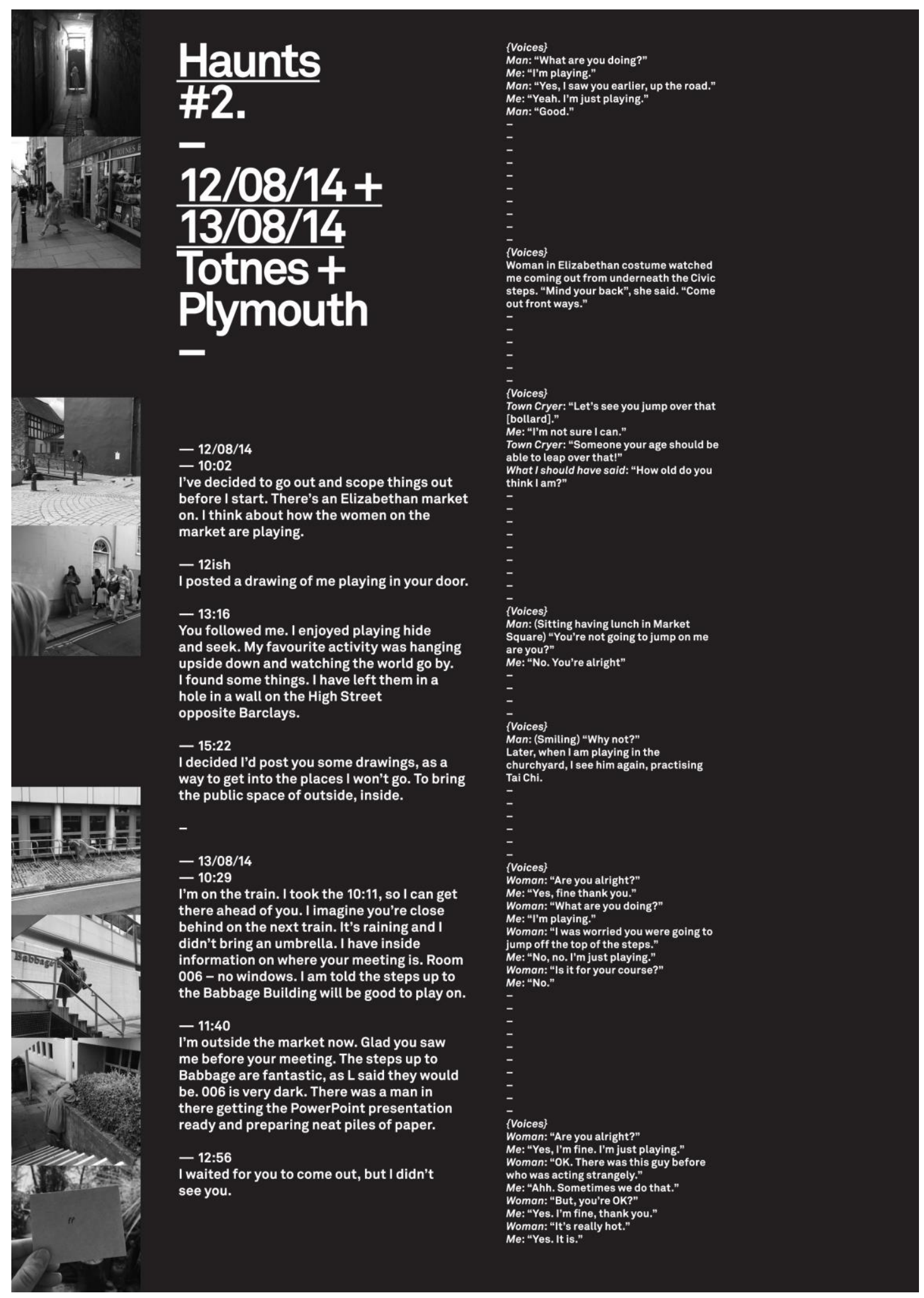


I named these performances Haunts $\# 1$ and \#2, and used these titles in the construction of my documentation. The word 'haunts' is commonly used to refer to a place someone frequents or typically spends time in, and for this version of the practice I was going to be occupying my examiners 'haunts' - the places that are known to them and that they visit regularly; their territory. Haunts can also be used to describe something disturbing, present and on a person's mind, and this seemed to relate both to my occupation of the streets - as an interruption - and the idea that I would be on my examiners' minds, and that they would be on mine.

\section{Methods}

Haunts involved several emails between my examiners leading up to the days that I was planning on 'stalking' them. The level of detail I needed meant that I built up much more knowledge of each of my examiners than an actor or performer typically knows of their audience. A one-to-one intimacy in Haunts was achieved through knowledge of my examiners' schedules, an indication of their regular routines, knowledge of the routes they travel, an idea of what time they will get up, eat lunch, drink coffee, and go home, glimpses of the inside of their work places and homes, and glimpses of their partners and colleagues.

For Haunts \#1 in London, I was located mostly outside my examiner's workplace. For Haunts \#2 I was located outside my examiner's home in Totnes, and for a short time her place of work in Plymouth. Because I had access to my examiner's front door in Haunts \#2, I extended the concept of play from physical action to also include making simple sketches of myself playing, which I would post through my examiner's front door. The integration of these sketches was not carefully planned, and simply became part of the improvised play activity. They were a response to the presence of the private space of my examiner's home that I could not enter, and a desire to play with the boundary between those spaces of private and public.

Using a mobile phone camera my partner David Penny took photographs of me performing in London, Totnes and Plymouth for Haunts. It was important that the images were captured in the most covert manner, and the use of a mobile phone camera achieved this. David kept a distance from me and many of the more close-up shots were taken when fewer people were around, so that his presence would not affect people's experience of the performance.

The written text of Haunts contains several statements that describe how I am feeling and what I am thinking about whilst undertaking the practice. My research practice has foregrounded a situated perspective, which was influenced by Donna Haraway's assertion that the partiality and position of the researcher is an important part of the work (1988). This is reflected in the documentation of Haunts, where personal thoughts and feelings reveal what is on my mind, drawing connections between my experience of public places and the concerns of the research.

Throughout both of the Haunts performances, I kept a diary in which I wrote down how I felt and reflected on things that were happening throughout the days. This was influenced by Jill Magid's diary entries for her project, Evidence Locker (2004), functioning as exposure of my own private thoughts, feelings and observances. The 
artist pages also document responses I received from members of the public who witnessed my practice.

\section{Findings}

\section{Unknowability}

In their covert nature, the photographs that have been taken are from the position of someone who is following. In many of the images, the status of the photographer is detective-like with shots taken from across the road or from within a crowd. However, the final image in Haunts \#2 is a close up of an envelope held in someone's hand. It's not clear who is holding this. It could be evidence discovered by an anonymous detective-photographer, or it could be the performer's hand. It could be the hand of the subject in the documentation who is not named but described through the secondperson pronoun 'you', 'you're'. This ambiguity over who is watching, whose perspective we are seeing, who the subject is, who I am and what the relationship is between each party involved creates a status of unknowability. In my practice, becoming less 'knowable' developed as a powerful position against possessive spectatorship and authoritarian ownership in spaces of the public built environment and related to my conception of developing 'romantic space' through performance.

The concept of 'romantic space', which developed in my thesis through my reading of the philosophy of Diotima in Plato's Symposium (1999), alongside Luce Irigaray's The Way of Love (2002) and Roland Barthes' A Lover's Discourse (2002), is typified by qualities such as intimacy, exchange, dialogue, intersubjectivity, presence, unknowability, chaos, multiplicity, uncertainty and fragmentation. The 'unknowable' features in Barthes' A Lover's Discourse as a frustration for the subject to not fully know their object of desire, which places knowledge of the self into question. Barthes' unknowability results in the subject gaining a sensory connection to the other, in lieu of a cognitive knowing and understanding (2002, 134-135).

For someone looking at the Haunts documentation, their role within the practice and the document is not clear, shifting between detective, someone known to the performer, the performer herself, the subject of the document, and the self. The photographs help to bring the viewer of the documentation towards the practice and the documentation as someone who is located within it, rather than being the distanced observer or reviewer of documentary material.

\section{Authority and Power}

Support is suggested in the form of a glance and a smile, or from a more direct comment, such as from the man in Totnes who asked me what I was doing and replied, 'good', in a way that felt as if it was an abbreviation for 'good for you!' Similarly, another man in Totnes said, 'why not?' when he saw me playing. A man in London commented that my sidestepping was very good and admitted that he had tried a similar action and couldn't do it as well. Comments of support are some of the nicer responses I have received, but they also function as a form of authorisation or permission. This corresponds with what Ursula Hofbauer and Friedmann Derschmidt describe as a culture of 'permits' in the public, built environment. They explain that this is 'the assumption that only that which is explicitly permitted is not forbidden' 
(2010: 217). In my experiences, there are some people within public spaces (often, but not always, men) who informally adopt a role of 'permitter' effectively policing the grey area of what is not explicitly forbidden.

Supportive comments can also be given in the form of a challenge, such as the Town Cryer in Totnes who said, 'let's see you jump over that [bollard]' to which I replied, 'I'm not sure I can' and he said, 'someone your age should be able to leap over that!' This kind of challenge is interesting because it registers that my practice is not very impressive and it locates me as young, childish and therefore, subordinate. I reflected in the Haunts documentation that I should have said to him, 'how old do you think I am?' as a way to answer back and raise a question around my perceived age.

The exclusivity of public urban places, and the extent to which women in particular struggle to feel a sense of belonging in urban environments has been explored in much research (Massey 1994, Ainsley 1998, Rendell et al. 2000). In my experiences, one process by which power is enacted socially in public space is through the verbal comment that becomes unidirectional in my fear to respond to it. It reflects Michel Foucault's theories of power in Discipline and Punish (1991). Martin Jay states that Foucault applied the panoptican notion of an exercise of power - its singular, imposing and unidirectional perspective - to that of certain uses of language. Jay explains how in Madness and Civilisation, Foucault 'recognised the linguistic strategy of Freud as another form of observation, of surveillance, through the monologue that is applied to the patient' (1986: 181). I would argue that this same monologic process of power is inherent in the gendered social construction of the public built environment.

\section{Discipline}

Responses of checking are sometimes related to people's concern over my safety or sometimes for their own safety. In Plymouth, two different women stopped me to ask if I was 'alright?' one woman said, 'I was worried you were going to jump off the top of the steps', whilst another said 'But, you're OK?' In both these cases, I am perceived as someone who is mentally ill and who poses a threat to myself (possible others). It is interesting that my activity of playing is readily interpreted as a sign of mental illness; it is perceived as not normal for a woman to behave in this way and it is unthinkable to many that a woman of sound mind would want to play in the street. At the risk of depreciating what are clearly caring interventions, there is a question around whether this kind of response functions, at the same time, as a form of behavioural discipline, perhaps in some way resulting from, or a more organically produced form of, 'soft paternalism' (Jones et al. 2011).

This signifier of behavioural discipline is also visible in my highlighting of the announcement on the train that asks people to keep a look out for suspicious behaviour, which is indicative of contemporaneous society and a collective anxiety about the (very real) possibility of a terrorist attack. The announcement and other announcements such as this, ask 'us' (good citizens of the UK), to be surveillance monitors and to keep an eye on each other. My comment, that 'I wonder what kind of thing gets reported' is a reflection on how my playing in public urban spaces might be understood as 'suspicious', and has indeed been considered as such by people throughout my practice. 
In the images presented within Haunts, many of the actions performed appear to involve tracing the edges of street objects. For example, tracing the perimeter of paving stones, or climbing along railings that line the edges of buildings, or the handrails alongside steps. This practice can be described as 'skirting', to move along the edges, to go around, to avoid the centre and to be indirect. This positioning of the practice reflects the adopting of 'edgeland' (Shoard 2002) status within local spaces of the built environment. It also locates the practice as being on the outskirts of dominant (feminine) practices of movement and physical activity in this type of place, and might reflect a behavioural discipline resulting from my own occupation and practising of urban spaces, in that I am avoiding taking up the central ground.

\section{Productivity}

Alongside these responses are those from people who try to understand what I am doing as purposeful activity. For example, two separate women in London asked me about or commented on my practice as 'exercise'. In the documentation for Haunts I remark that I am pleased that the activity is interpreted in this way, because it suggests that it is not read as a form of skilled practice or dance, which might be taken as entertainment or street theatre. It was important to me to try and create a practice that could not be consumed as entertainment and that subverted public urban space by being unprofitable or unproductive.

Much of the literature on urban space and on performance mentioned in this article raises a concern and critique of public urban space as commercially orientated and primarily concerned with the flow of capital (see also Lefebvre 2004). In the practice of Haunts, the activity I was performing was not seen as profitable in the monetary sense - I was not asking for money and the activity is not read as a professional presentation of any kind - so, in lieu of this, my practice has been framed by several commentators as exercise; a different form of profit.

In the documentation for Haunts \#2, I talk about the presence of the Elizabethan Market, which is a regular event in Totnes. I reflect on how the women on the market stalls, dressed as they are in Elizabethan costumes, are themselves playing, albeit through a historical and economically useful framing. This comment draws a contrast between the Elizabethan market sellers play and what I am doing - an unsanctioned, non-useful and un-organised form of play. It is these features of not being organised, authorised and sanctioned that make my activity strange.

\section{'Clews'}

There are several comments within the documentation of Haunts that deal with moments of synchronicity between my practice for Haunts and the previous moments of practice undertaken throughout the research, which highlight how much the research developed through a consistent thinking about and musing over the practice, and that insights developed through my accumulated engagements with different urban sites.

In the documentation for Haunts \#1 I talk about my costume and a dream I have had to add rubber to the forearm section of the dress. My costume developed considerably 
throughout the research, as I played with different feminine representations. One of my earliest conceptions of a feminine character was my adoption of a dress referencing popular depictions of 'Alice' from Lewis Carroll's 1865 novel Alice's Adventures in Wonderland. Later in the documentation I identify that there is a show on at the theatre opposite my examiner's building called 'Wonderland' and state, 'it's not an Alice show'. I also talk about the garden behind the theatre having rows of different coloured roses, which relates to the Alice's Adventures in Wonderland story.

Though someone reading this documentation wouldn't necessarily have any knowledge of the previous versions of my dress, bringing 'Alice' into contact with the current practice raises a connection, which is likely to be drawn into their reading. It suggests a possible identification of the urban sites in which I am located as being like the nonsensical world of 'Wonderland', and it links to my performance and representation as 'Alice-like'. The final version of the dress was made in a grey cotton and was designed to reference the previous Alice dress, and other fictional female characters, but to be far removed from an identifiable character and the colourful, cheerful look of something 'fairytale'.

'Alice' became a 'clew' throughout my research. Robin Nelson articulates the 'clew' as a play on the word 'clue' embodying an archaic meaning of the word as a thread to describe a thread that can be traced through a research project $(2013,10 \& 27)$, and this is echoed in the documentation for Haunts, where Alice becomes a clue that refers back to earlier versions of my practice.

Another connection to previous practice that features in Haunts \#1 is my mention of pillars outside Uxbridge tube station. I state, 'I found some pillars just like the ones outside the Grosvenor Hotel in Chester. They felt like an old friend.' The pillars were very similar to ones I played on outside the Grosvenor Hotel in Chester's Eastgate Street. There is implicit knowing in this moment; that there is something of Chester to Uxbridge. I am making a connection between the apparent and visible wealth of both places. This comment also highlights how aspects of urban places - pillars, railings, planters, etc., become part of a symbolic language that is readable up and down the country in different cities and towns.

\section{Conclusion}

The different modes of knowledge production and dissemination that constitute the practice as research bandwidth offers multiple opportunities for audiences outside of the established hegemonic knowledge economy of the academy to engage with research. The status of unknowability engendered by my performance documentation helps to encourage oblique and perceived connections to the material, avoiding the supposed objectivity of traditional modes of academic enquiry and allowing for a range of responses and knowledge outcomes conditioned by the individual and a reflection on their own experiences of public space.

The visual nature of the performance document allows the viewer to see my specific bodily characteristics and the presentation of femininity I have adopted, rather than to read a description of it. This allows the viewer to orient themselves in relation to the gender presentation I have utilised, from their own gendered, social standpoint. Moments of symbolism, or inter-cultural references - to Alice and to the architectures 
of other cities - are likely to infect a reading of this documentation, and function as another point of orientation for the reader depending on their previous knowledge practical or otherwise - of the references made.

In relation to Auslander's argument that performance documentation functions as another performance moment, my documentation presented in Haunts was influenced considerably by the work of Jill Magid. By not giving clear details, providing fragments of information, and including personal feelings, the reading process becomes an investigation, requiring an active engagement that draws the reader into the work, instead of allowing the reader to adopt an outsider perspective - a rational, spectatorial distance. The reader therefore becomes part of the document/performance through their construction of a response and their own individual discovery of knowledges.

The portrait of public urban space that appears within an analysis of Haunts is one containing several forms of subtle disciplining that is connected to gender. Exercises of power operate through the informal adoption of social roles that grant permission, comment upon and challenge 'strange' behaviour. The culture of productivity and profit within public urban space is socially enacted through the narrative that is applied to my activity by members of the public.

Performance documentation, as another site of knowledge production within the practice as research $\mathrm{PhD}$, is therefore very much like an experience of the practice live and in the moment; the knowledges it produces are multiple, situated and specific to the individual and their embodied experience of the material.

\section{References}

Ainsley, R. (ed.) (1998) New Frontiers of Spaces, Bodies and Gender, London: Routledge

Auslander, P. (1999) Liveness: Performance in a Mediatized Culture, London and New York: Routledge

Auslander, P. (2006) 'The Performativity of Performance Documentation' PAJ: A Journal of Performance and Art 28(3)

Barthes, R. (2002) A Lover's Discourse: Fragments (Trans. Richard Howard) London: Vintage Books

Bennett, R.S., Whitaker, K.G, Woolley Smith, N.J. and Sablove, A. (1987) 'Changing the Rules of the Game: Reflections Towards a Feminist Analysis of Sport' Women's Studies International Forum 10(4), 369-379

Birrell, S. and Richter, D.M. (1987) 'Is a Diamond Forever? Feminist Transformations of Sport' Women's Studies International Forum 10(4), 395409

Borden, I. (2001) Skateboarding, Space and the City: Architecture and the Body. Oxford and New York: Berg 
Bryson, L. (1987) 'Sport and the Maintenance of Masculine Hegemony' Women's Studies International Forum 10(4), 349-360

Carroll, L. (1865) Alice's Adventures in Wonderland. London: Macmillan and Company

De Marinis, M. (1985) 'A Faithful Betrayal of Performance: Notes on the Use of Video in Theatre' New Theatre Quarterly 1(4)

Dogtown and Z-Boys (2001) Directed by Stacey Peralta [DVD]. USA: Sony Pictures

Etchells, T. (1999) Certain Fragments: Contemporary Performance and Forced Entertainment. London and New York: Routledge

Foucault, M. (1991; 1977) Discipline and Punish: The Birth of the Prison (trans. Alan Sheridan) Middlesex: Penguin Books

Freeman, J. (2010) Blood, Sweat and Theory. Farringdon: Libri Publishing

Hand, C. (2004) 'Jill Magid: Retrieval Room and Evidence Locker' [online]. Available at: www.evidencelocker.net/img/catalogue.gif. Accessed 15th May 2014

Haraway, D. (1988) 'Situated Knowledges: The Science Question in Feminism and the Privilege of Partial Perspective' Feminist Studies 14(3)

Hofbauer, U. and Derschmidt, F. (2010) 'Horror Vacui' in Whybrow, N. (ed.) Performance and the Contemporary City: An Interdisciplinary Reader, Basingstoke and New York: Palgrave Macmillan

Holert, T. (2009) 'Art in the Knowledge-based Polis' [online]. Available at: http://www.e-flux.com/journal/art-in-the-knowledge-based-polis/. $\quad$ Accessed $11^{\text {th }}$ August 2015

Irigaray, L. (2002) The Way of Love (Trans. Heidi Bostic and Stephen Pluháček). London and New York: Continuum

Jay, M. (1986) 'In the Empire of the Gaze: Foucault and the Denigration of Vision in Twentieth-century French Thought' in Couzens Hoy, D. (ed.) Foucault: A Critical Reader. Oxford and New York: Basil Blackwell Ltd

Jones, R. and Pykett, J. and Whitehead, M. (2011) 'The Geographies of Soft Paternalism in the UK: The Rise of the Avuncular State and Changing Behaviour after NeoLiberalism' Geography Compass 5(1), 50-62

Kaye, N. (2000) Site-specific Art: Performance, Place and Documentation. London and New York: Routledge 
Kershaw, B. and Nicholson, H. (eds.) (2011) Research Methods in Theatre and Performance. Edinburgh: Edinburgh University Press

Kershaw, B with Miller, L \& Whalley, J and Lee, R. \& Pollard, N. (2011) 'Practice as Research: Transdisciplinary Innovation in Action' in B. Kershaw and $\mathrm{H}$. Nicholson (eds.) Research Methods in Theatre and Performance. Edinburgh: Edinburgh University Press

Knijnik, J. (2012) 'Visions of Gender Justice: Untested Feasibility on the Football Fields of Brazil' Journal of Sport and Social Issues 37(1), 8-30

Lefebvre, H. (2004) Rhythmanalysis: Space, Time and Everyday Life, London and New York: Continuum

Magid, J. (2004) 'Evidence Locker' [performance documentation]. Available at: www.evidencelocker.net. Accessed 15 May 2014

Massey, D. (1994) Space, Place and Gender, Cambridge and Oxford: Polity Press

Nelson, R. (2013) Practice as Research in the Arts: Principles, Protocols, Pedagogies, Resistances. Basingstoke: Palgrave Macmillan

Nelson, R. (2006) 'Practice as Research and the Problem of Knowledge' in Performance Research 11(4)

PARIP (n.d.) 'Overview', [online]. Available at http://www.bris.ac.uk/parip/introduction.htm. Accessed 17 April 2015

Piccini, A. (2002) 'A Historiographic Perspective on Practice as Research', [online]. Available at: http://www.bris.ac.uk/parip/t ap.htm. Accessed 17 April 2015

Phelan, P. (1993) Unmarked: The Politics of Performance. London and New York: Routledge

Plato (1999) Symposium. Penguin

Rendell, J., Penner, B. and Borden, I. (eds.) (2000) Gender, Space, Architecture: An Interdisciplinary Introduction, London and New York: Routledge

Richman, E.L. and Shaffer, D. R. (2000) 'If You Let Me Play Sports: How Might Sport Participation Influence the Self-esteem of Adolescent Females?' Psychology of Women Quarterly 24,189-199

Shoard, M. (2002) 'Edgelands' in J. Jenkins (ed.) Re-making the Landscape: The Changing Face of Britain. London: Profile 
Strandbu, Å. and Hegna, K. (2006) 'Experiences of Body and Gender Identity Among Young Female Norwegian Basketball Players' Sport and Society 9(1), 108-127

Vaughter, R.M., Sadh, D. and Vozzola, E. (1994) 'Sex Similarities and Differences in Types of Play in Games and Sports' Psychology of Women Quarterly 18, 85-104

Dani Abulhawa is senior lecturer in Performance at Sheffield Hallam University, and completed her practice as research $\mathrm{PhD}$ with Plymouth University in 2015. She has written a chapter for the forthcoming publication Philosophical Perspectives on Play (summer 2015).

Email: d.abulhawa@shu.ac.uk 